\title{
Lateral inhomogeneity deduced from 3-D magnetotelluric modeling around the hypocentral area of the 1984 Western Nagano Prefecture earthquake, central Japan
}

\author{
Takafumi Kasaya* and Naoto Oshiman \\ Disaster Prevention Research Institute, Kyoto University, Kyoto 611-0011, Japan \\ (Received November 4, 2003; Revised April 25, 2004; Accepted April 26, 2004)
}

\begin{abstract}
Earthquake swarms have been observed since 1976 in the southeastern region of Mt. Ontake, where the 1984 Western Nagano Prefecture earthquake (M6.8) occurred. Most earthquake swarm activities show a dense distribution in a narrow area and at shallow depths. We have carried out forward 3-D magnetotelluric modeling for the data set observed around the focal region of the earthquake swarms. An initial 3-D image was constructed based on previous 2-D magnetotelluric analysis results. The resistivity structure shows remarkable lateral inhomogeneity: a low resistivity zone is located at shallow depth around the center of the study area and the low resistivity zone is surrounded by a high resistive structure and its shape is about a 4-km cube. This feature agrees well with the distribution of the degree of water saturation deduced from seismic information. Hypocenters of recent seismicity are distributed around an area between the resistivity boundary and the relatively high-resistance region. This fact strongly suggests that earthquakes in the study area are triggered by fluid (water) in the crust.
\end{abstract}

Key words: 3-D MT modeling, resistivity structure, lateral inhomogeneity, earthquake swarm, Western Nagano Prefecture earthquake.

\section{Introduction}

The 1984 Western Nagano Prefecture earthquake of M6.8 occurred on 14 September, 1984 at the southern foot of Mt. Ontake in central Japan. In this region, earthquake swarm activities began in August 1976. The first eruption of Mt. Ontake in history took place in October 1979 (Hori et al., 1982). Steady earthquake swarm activities continued after the 1979 eruption. Although rupture did not appear on the earth surface, the spatial distribution of aftershocks extended in a direction of the strike, $\mathrm{N} 70^{\circ} \mathrm{E}$. Hypocenters of aftershocks concentrated along the earthquake fault and at both ends. The maximum depth in the eastern side of the aftershock area was about $6 \mathrm{~km}$. It became $10 \mathrm{~km}$ at the western end (Horiuchi et al., 1992). After aftershock activities subsided along the fault, continuous seismic activities were observed again on the eastern side of the fault. At present, seismic activities occur in the same area where the earthquake swarm was observed before the main shock. Seismological investigations suggest that crustal fluid plays an important role in processes controlling seismic activity in the Ontake region (e.g., Tanabe, 1996; Umeda and Ito, 1998; Takeda et al., 1999). Electrical resistivity is a very sensitive parameter for detecting the fluid in the Earth's crust. Fluid is usually detected as the low resistivity. For that reason, the magnetotelluric (MT) survey is very useful method for

\footnotetext{
*Present address: Deep Sea Research Department, Japan Agency for Marine-Earth Science and Technology, Kanagawa 237-0061, Japan.

Copy right(c) The Society of Geomagnetism and Earth, Planetary and Space Sciences (SGEPSS); The Seismological Society of Japan; The Volcanological Society of Japan; The Geodetic Society of Japan; The Japanese Society for Planetary Sciences; TERRAPUB.
}

investigating the relation between the fluid and earthquake generation. Recent two-dimensional (2-D) MT studies have detected the conductor near the seismogenic zones (Tank et al., 2003; Ogawa et al., 2001; Ogawa et al., 2002; Mitsuhata et al., 2001). Results of those studies show the fact that foci are distributed in relatively resistive zones or around boundaries between resistive and conductive zones. Mitsuhata $e t$ al. (2001) suggested that the permeation of the fluid from the low resistive area to the resistive zone become a trigger of the earthquakes.

Using data obtained with wide-band MT measurements, Kasaya et al. (2002) carried out 2-D analysis along two profiles across the earthquake fault of the 1984 Western Nagano Prefecture earthquake (Fig. 1): one was in the low seismicity portion of the fault (A- $\mathrm{A}^{\prime}$ profile); the other was in the high seismicity portion (B-B' profile). The resistivity structure along the A-A' profile shows high resistivity and a homogenous structure. On the other hand, the resistivity structure has a clear boundary at the center of the B-B' profile. This boundary divides the structure along the $\mathrm{B}-\mathrm{B}^{\prime}$ profile into two resistivity blocks. Its location coincides with that of the earthquake fault. A conductor was found at depths greater than $8 \mathrm{~km}$ to the northwestern side of the earthquake fault. The depth of the upper boundary of the conductor is consistent with those of seismic reflectors (Mizoue and Ishiketa, 1988; Inamori et al., 1992).

Many studies have addressed three-dimensional (3-D) MT modeling in recent years. Garcia et al. (1999) reported that 2-D analysis gives a good approximation for 3-D structure when a decomposition technique is adapted to the dataset. However they also pointed out the possibility that a 2-D 


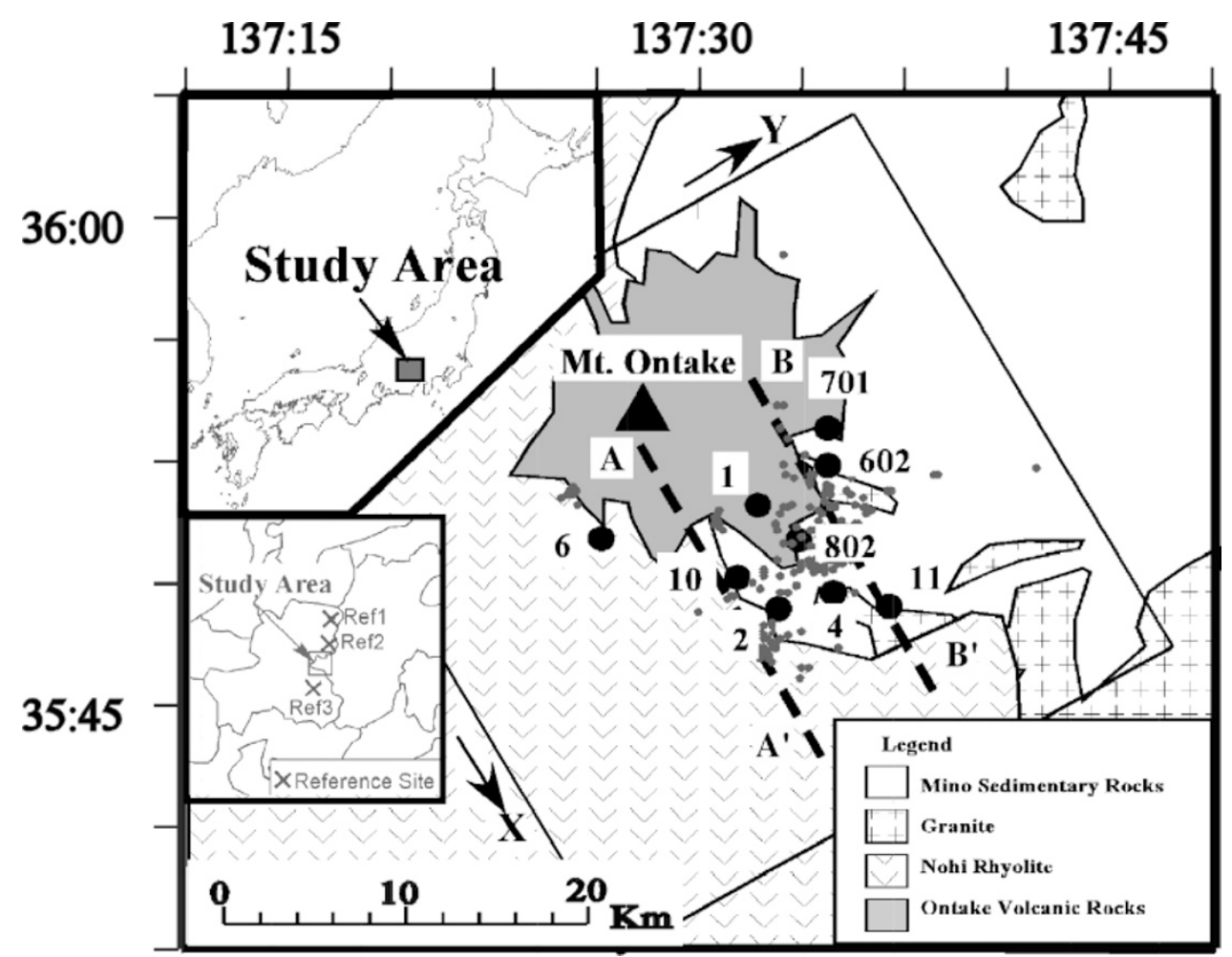

Fig. 1. Location map of nine MT sites chosen for 3-D modeling and a simplified geological map (GSJ, 1995). Small circles denote hypocenters. Two dashed lines, A- $\mathrm{A}^{\prime}$ and B-B' indicate the two profiles of the 2-D modeling conducted by Kasaya et al. (2002). Hypocenters of earthquakes from October to December 1995 are also shown in this figure.

model cannot resolve lateral variations along the strike direction for a 3-D structure.

Based on the 2-D model results obtained by Kasaya et al. (2002), this study applies 3-D resistivity modeling to the response data of the MT measurements to investigate lateral inhomogeneity in the resistivity structure around the hypocentral area of the 1984 Western Nagano Prefecture earthquake and earthquake swarm area in the southeastern foot of Mt. Ontake.

\section{MT Survey}

\subsection{Site location and geological setting}

As reported in Kasaya et al. (2002), wide-band MT measurements were conducted in the Ontake region shown in Fig. 1. The observed frequency range is from 384 to 0.0005 Hz. Measurements were taken for 2-4 nights at each observation site. A DC electric railway (JR Chuo-line) runs in the eastern side of the MT survey area. Consequently, strong noise results from leakage currents. Therefore, we established observation sites for applying remote reference processing (Gamble et al., 1979). Reference sites were located $40 \mathrm{~km}$ distant from the survey area to keep coherent noise from the electric railway from influencing the electric and magnetic records. However, reliable impedances at each site were obtained only at frequencies higher than $0.75 \mathrm{~Hz}$. Because the leakage current from the DC electric railway was very strong and electric field was especially disturbed. Unfortunately, some night trains runs on the east side of this study area from $1 \mathrm{a} . \mathrm{m}$. to $3 \mathrm{a} . \mathrm{m}$. and MT signal was very weak when we observed. Therefore, we could not use the lower frequency data.
Figure 1 shows locations of nine sites chosen for our 3D modeling, hypocentral distribution from October to December in 1995, and a simplified geological map (Geological Survey of Japan, 1995). Nine sites were selected for 3-D modeling to avoid topographic effects and uneven spatial site distribution. Hypocentral distribution were obtained by the high densely earthquake observation network of NIED. The two dashed lines in Fig. 1 indicate the 2-D profiles made by Kasaya et al. (2002). Mt. Ontake, which erupted in 1979, is located in the northwest portion of the MT survey area. The geological legend of Fig. 1 shows that the overall geological structure in this area can be divided into three blocks: Mesozoic era accretionary prism, granitic rocks and rhyolite, and Cenozoic era andesitic lava and volcanic outflows. In this area, Mesozoic accretionary prism (Mino belt) is oldest. It is widely distributes at northeast area. The Mino belt in this area continued its accretion process to latest Jurassic or earliest Cretaceous (Shuto and Otsuka, 2004). Thereafter, the accretionary prism uplifted and formed the skeletal structure of Central Japan. Rhyolite was formed during large-scale volcanic activity from the late Cretaceous era to the early Cenozoic era. Granite intruded into the Mino belt during the early Cenozoic era. The basement in this area comprises the rock types mentioned above. Moreover, those basements were covered by andesitic rock attributable to Mt. Ontake volcanic activity (Yamada and Kobayashi, 1988; Kimura and Yoshida, 1996).

New Energy and Industrial Technology Development Organization (NEDO) carried out electrical logging as part of a geothermal potential assessment (NEDO, 1988). They reported that resistivity values of basement rocks are relatively 


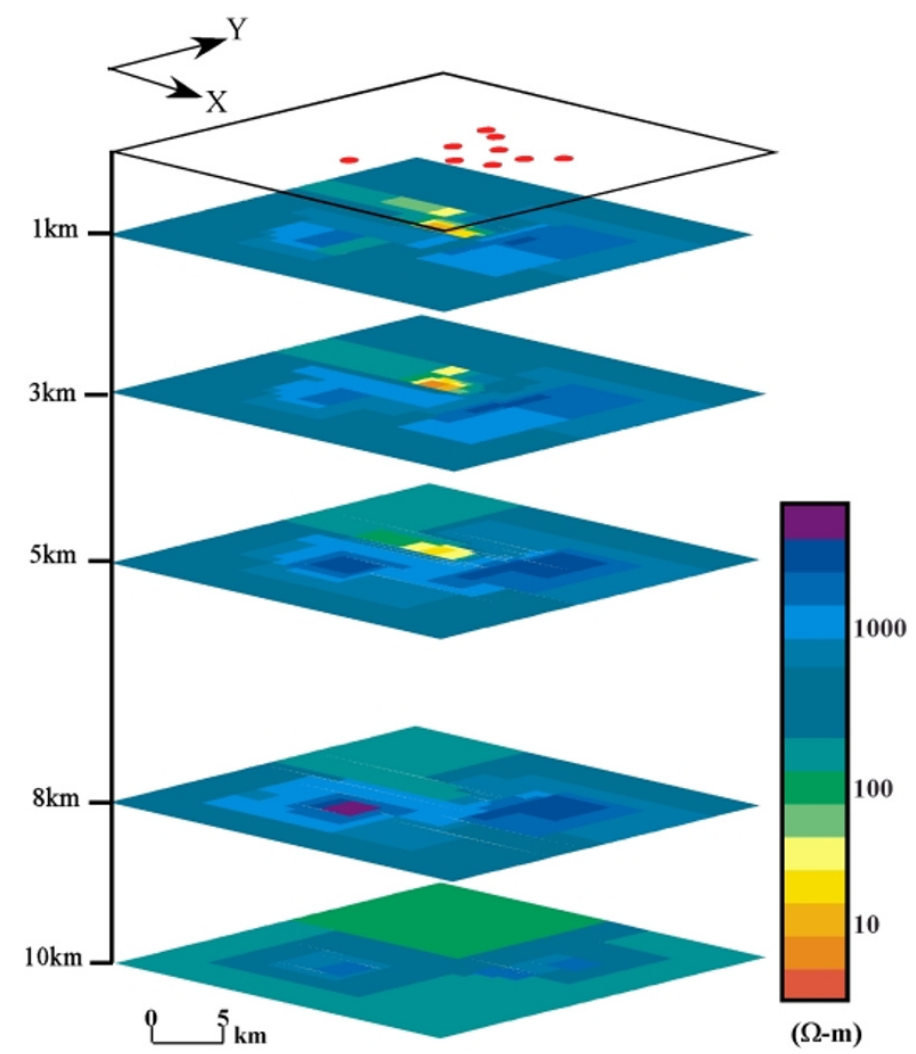

Fig. 2. The final 3-D resistivity structure at depths of $1,3,5,8$, and $10 \mathrm{~km}$, respectively.

high: granite and rhyolitic tuff showed $1000 \mathrm{~m}$ and sediments of the Mino belt showed 400-500 $\Omega \mathrm{m}$. The structure below the MT sites is expected to indicate high resistivity because the granite, the rhyolite and the Mino belt widely cover this study area (Yamada and Kobayashi, 1988; Kimura and Yoshida, 1996).

\subsection{Magnetotelluric data}

Observed MT responses are often influenced by local 3-D effects. The decomposition technique proposed by Groom and Bailey (1989) is useful for reducing such a local 3-D effect on responses and for estimation of a regional strike of a resistivity structure. In this paper, Groom-Bailey decomposed data were used for 3-D modeling. Some studies were used same procedure (Garcia et al., 1999; Ledo et al., 2000). Therefore we adopted the Groom and Bailey decomposition technique before applying responses to 3-D modeling. After correcting for shear and twist, strike angles were obtained for each observation site at the frequency ranges of 100-1 $\mathrm{Hz}$. The estimated direction is almost $\mathrm{N} 30^{\circ} \mathrm{W}$ or $\mathrm{N} 60^{\circ} \mathrm{E}$. The strike direction of the 1984 Western Nagano Prefecture earthquake fault is estimated $\mathrm{N} 70^{\circ} \mathrm{E}$ and the strong gradient belt in Bouguer anomaly has a trend of its strike along $\mathrm{N} 40^{\circ} \mathrm{E}$ (Shichi et al., 1992). Therefore, Kasaya et al. (2002) chose the direction of $\mathrm{N} 60^{\circ} \mathrm{E}$ as the regional strike.

Static shift and topographic effect are also serious problem for modeling. Currently, it is difficult to include these effects in 3-D resistivity model. Therefore, we examined these effects using other information. Kasaya et al. (2002) carried out 2-D modeling developed by Ogawa and Uchida (1996). This inversion technique can estimate static shift factors at each observation site. In the 2-D modeling result, static shift factors are very small. Shallow resistivity distribution obtained by CSAMT (Iio et al., 2000) showed good correlations with the geology and the well logging data (NEDO, 1988). This is another support for the small static shift in the region. The topography is another source of static shift. The distance to the steep slope of Mt. Ontake from the MT sites was more than $5 \mathrm{~km}$. Thus, the effect of the topography will be minor.

\section{3-D Modeling and Results}

Adopting the 3-D resistivity modeling techniques proposed by Mackie et al. (1993), we produced model calculations to construct a 3-D resistivity structure around the 1984 Western Nagano Prefecture earthquake region. The two 2D models obtained by Kasaya et al. (2002) were used as an initial model for constructing a 3-D model of the resistivity distribution. Model calculations were carried out through trial and error to elucidate the observed responses at each observation site. The rectangular area shown in Fig. 1 indicates the 3-D model core region of Mackie's modeling method for this study. The coordinate system of the 3-D model is rotated to the $\mathrm{N} 60^{\circ} \mathrm{E}$ (Fig. 1).

This study is intended to image 3-D resistivity distribution and to reveal lateral inhomogeneity of the resistivity structure, especially around the hypocentral region of seismic swarm activities at shallow depths $(<5 \mathrm{~km})$. Finally, we compare the resultant 3-D image with other geophysical information.

The horizontal size of the 3 -D model core is $35 \mathrm{~km} \times 35$ $\mathrm{km}$. The finest mesh sizes along the horizontal and vertical axes are 0.625 and $0.1 \mathrm{~km}$, respectively. The mesh becomes 

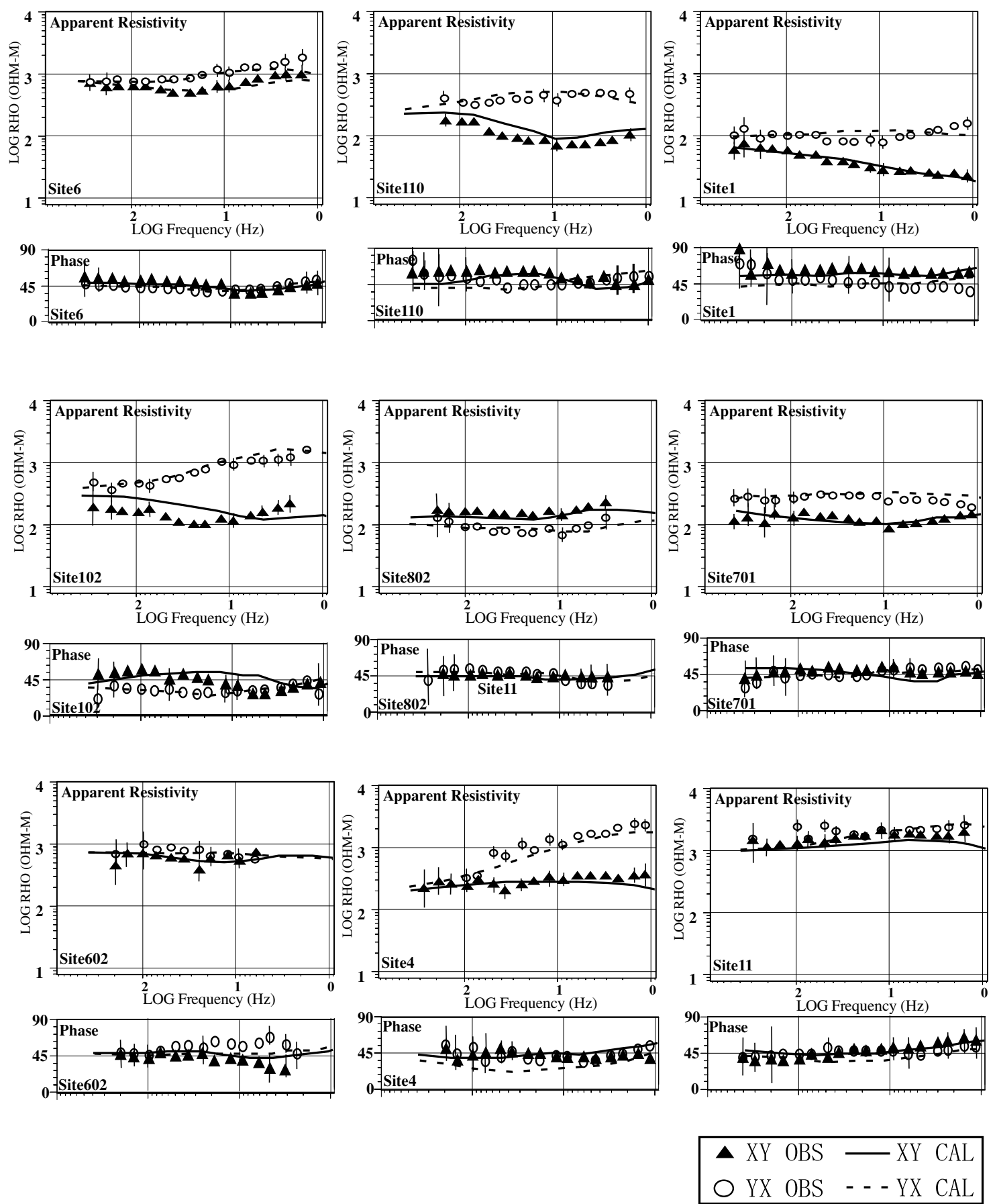

Fig. 3. Observed and calculated curves of the apparent resistivity and phase. Calculated ones are obtained from the final 3-D model shown in Fig. 2.

coarse as the elements distribute toward deeper or outer parts. The 3-D model core was divided into $28 \times 30 \times 20$. Figure 2 shows slices of the final 3-D resistivity model at depths of $1,3,5,8$, and $10 \mathrm{~km}$. Figure 3 shows the observed data and response curves that were calculated from the model. A general feature of the final 3-D resistivity structure is a relatively low resistivity region exists the northeastern part of the 3-D model core. This region corresponds to the conductive region around the NW side found along the B-B' profile of the 2-D model in Kasaya et al. (2002). A conductive body obtained along the $2-\mathrm{D}$ profile $\mathrm{B}^{-\mathrm{B}^{\prime}}$ is also apparent at depths from $1 \mathrm{~km}$ to $5 \mathrm{~km}$ in the central region of the 3-D model core. The resistivity of this region is esti- mated at 5-50 ohm-m in the 3-D model. On the other hand, resistivity is relatively high in other areas at the model core. A resistive body surrounds its highly conductive body on the northern side. If this conductive body did not exist, the calculated response curves at Sites, 1, 602 and 802, could not explain the observed responses well in the range from 192$0.75 \mathrm{~Hz}$. Beneath the conductor, depths of 5-8 km under the conductor are more resistive (200-700 ohm-m). The resistivity of the entire structure becomes smaller at depths greater than $8 \mathrm{~km}$ in the 3-D model core, in agreement with Kasaya et al. (2002). This is required to fit the observed phase, which decreases at lower frequency. However, the sensitivity at this structure is not high. 

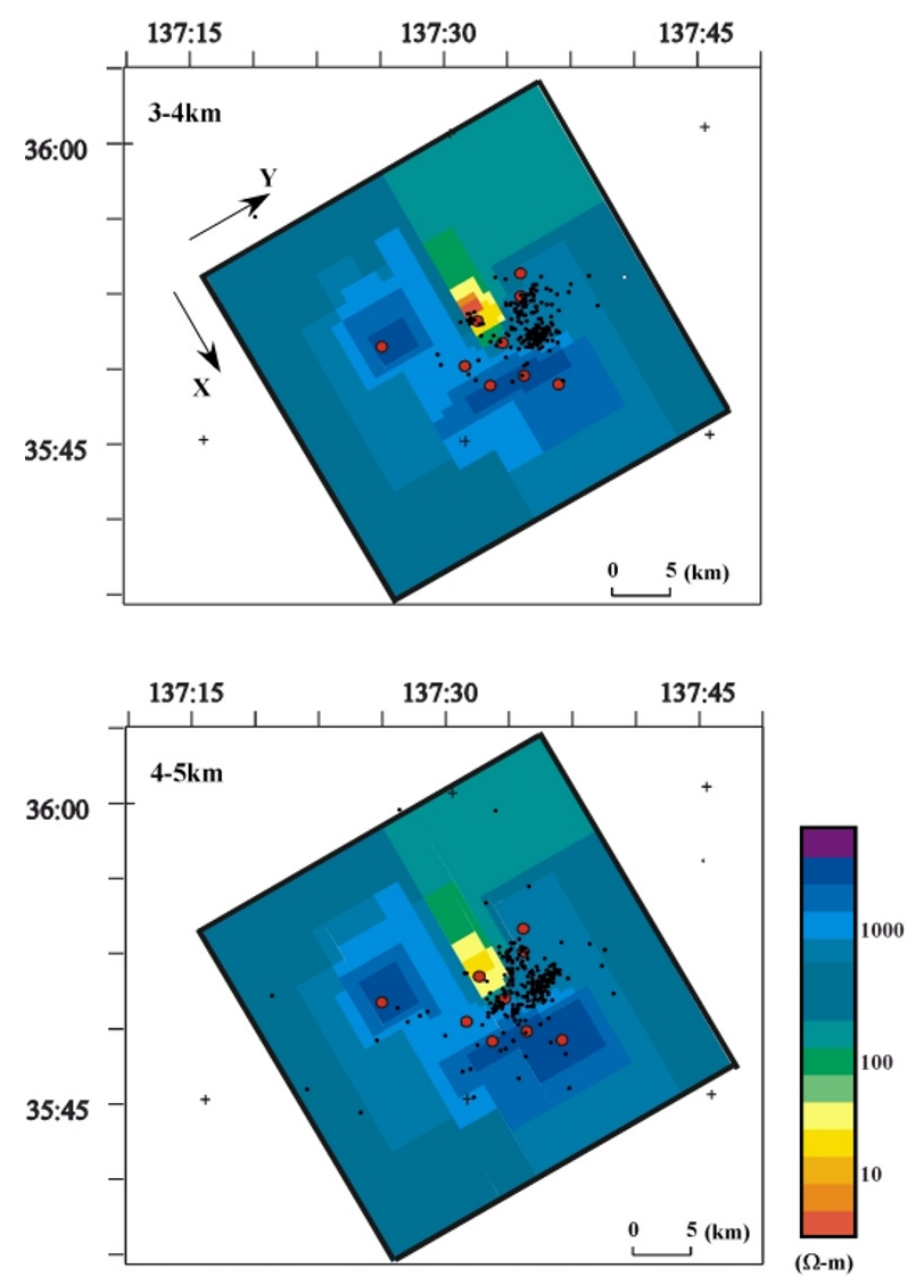

Fig. 4. Horizontal section of the 3-D resistivity structure model together with hypocentral distributions at depths of 3-4 and 4-5 km. Read circles show each observation sites. Hypocenters of earthquakes from 1995 to 1996 are also shown in this figure.

\section{Discussion}

Figure 4 shows the 3-D resistivity structure together with hypocentral distributions at depths of 3-4 (Fig. 4, upper) and 4-5 km (Fig. 4, lower). Figure 4 also shows epicenters of earthquakes from 1995 to 1996 . Comparison of the 3-D resistivity structure and the hypocentral distribution indicates that earthquakes appear to distribute around the boundary between the low and high resistive bodies rather than inside the conductor. In particular, the distribution of earthquakes is concentrated at the northeastern and southeastern sides of the low resistivity body. A possible explanation of this is that the shear strength becomes lower to avoid accumulating large strain because cracks saturated with water develop inside the low resistive body.

Takeda et al. (1999) estimated crack density and the degree of water saturation from the $\mathrm{Vp} / \mathrm{Vs}$ ratio in the crust to a 4-km depth. Their study addressed the cause of high seismicity in the Ontake region. They found that earthquakes occurred in the region where the degree of saturation was low. In addition, that less-saturated area surrounded an area of higher saturation. Earthquakes did not occur in that more saturated area. Similarly to the result of Takeda et al. (1999), the highly saturated area corresponds to the low resistivity area and the low saturated area agrees with the high resistive body at a depth of $4 \mathrm{~km}$. Furthermore, Saeki and Umeda
(1988) pointed out that some open cracks distribute at $4 \mathrm{~km}$ depth around the center of this study area, supporting the existence of cracks that can contain fluid. In general, the electrical resistivity has a deep connection with existence of the pore fluid. It especially depends upon the fluid connectivity and the degree of saturation (Glover et al., 2000). The low resistivity area consists of fluid. Takeda et al. (1999) concluded that earthquakes might occur when fluid in the highly saturated area begins to flow into the little saturated cracks. Namely, fluid flow from low resistivity area to relatively high area occurred earthquakes when the fluid flow decreases frictional strength because pore pressure increases.

On the other hand, Kasaya et al. (2002) pointed out existence of the deep conductor below the study area and that the distribution of the low resistivity zone agrees with the depth of the top of the seismic reflector. Tanabe (1996) revealed that the depth of the seismic reflectors before the occurrence of the 1984 western Nagano Prefecture earthquake was shallower than after the earthquake. The study concluded that the upper surface of fluid, which is distributed widely in the lower crust, was at a shallower depth. Furthermore, Sano et al. (1986) and Sano et al. (1998) pointed out that ${ }^{3} \mathrm{He} /{ }^{4} \mathrm{He}$ ratio of bubbling gases increased after the main event. This fact supports water movement in the crust because ${ }^{3} \mathrm{He}$ is inferred to have magmatic origin. 
Therefore, as mentioned in Kasaya et al. (2002), free water that is dehydrated from magma forms a deeper conductor below a depth of $8 \mathrm{~km}$. The water rises to the conductive body at a depth shallower than $5 \mathrm{~km}$. We suggest that fluid movement causes shallow earthquake swarm activity from the conductive body.

\section{Conclusions}

We reanalyzed MT data of the 1984 Western Nagano Prefecture earthquake region, constructing a 3-D resistivity structure to compare it with other geophysical information. The final 3-D resistivity structure clarified the horizontal heterogeneity of the resistivity structure. These results give the information of the strike direction of 2-D model.

Though aftershocks were distributed along the earthquake fault plane, present activity of earthquakes concentrate around the center of our study area. We discussed correlations among the 3-D resistivity structure, seismicity, and other geophysical features around the hypocentral area of the 1984 Western Nagano Prefecture earthquake. This study obtained the following results.

(1) A low resistivity block was detected as about a 4-km cube at a shallower depth with a relatively high resistive region (500-1000 ohm-m) surrounding it. This feature agrees well with distribution of the degree of water saturation.

(2) Many earthquakes occurred around the boundary separating the relatively high-resistivity area and the conductor. In contrast, few earthquakes occurred inside the high resistivity area.

Acknowledgments. The authors gratefully acknowledge Prof. Y. Iio of Kyoto University and Mr. D. Uehara for their permission to use various MT and hypocentral data. We are deeply grateful to Prof. N. Sumitomo for his advice and suggestions. We also thank the Research Group for Crustal Resistivity Structure Japan for MT data acquisition in this study field. We thank the officers of Otaki and Mitake Village and Agematsu Town for their support in our MT surveys, and Local Forest Offices of Otaki, Kisofukushima, and Agematsu for their permission for MT deployment. We would like to thank Malcolm Ingham and an anonymous reviewer for their valuable suggestions on an earlier version of the manuscript. Several figures were made using GMT produced by Wessel and Smith and Geotools MT software produced by Geotools Corporation.

\section{References}

Gamble, T. D., W. M. Goubau, and J. Clarke, Magnetotellurics with a remote magnetic reference, Geophysics, 44, 53-68, 1979.

Garcia, X., J. Ledo, and P. Queralt, 2D inversion of 3D magnetotelluric data: The Kayabe dataset, Earth Planets Space, 51, 1135-1142, 1999.

Geological Survey of Japan (GSJ), Geological Map of Japan 1:1,000,000, 3rd Edition, CD-ROM version, Digital Geo-science Map G-1, 1995.

Glover, P. W. J., P. J. Hole, and J. Pous, A modified archie's law for two conducting phases, Earth Planets. Sci. Lett., 180, 369-383, 2000.

Groom, R. W. and R. C. Bailey, Decomposition of magnetotelluric impedance tensors in the presence of local three-dimensional galvanic distortions, J. Geophys. Res., 94, 1913-1925, 1989.

Hori, S., H. Aoki, and T. Ooida, Focal mechanisms of the earthquake swarm southeast of Mt. Ontake, Central Honshu, Japan, Zisin, 35, 162-169, 1982 (in Japanese with English abstract).

Horiuchi, S. and The members of the 1986 Joint Seismological research in Western Nagano Prefecture, Hypocenter locations by a dense network, $J$. Phys. Earth, 40, 313-326, 1992.

Iio, Y., R. Ikeda, K. Omura, Y. Matsuda, Y. Shiokawa, M. Takeda, and D. Uehara, Conductivity structure of seismogenic region in the western Nagano Prefecture, BUTSURI-TANSA, 53, 56-66, 2000 (in Japanese with English abstract).
Inamori, T., S. Horiuchi, and A. Hasegawa, Location of mid-crustal reflectors by a reflection method using aftershock waveform data in the focal area of the 1984 Western Nagano Prefecture Earthquake, J. Phys. Earth, 40, 379-393, 1992.

Kasaya, T., N. Oshiman, N. Sumitomo, M. Uyeshima, Y. Iio, and D. Uehara, Resistivity structure around the hypocentral area of the 1984 Western Nagano Prefecture earthquake in central Japan, Earth Planets Space, 54, 107-118, 2002.

Kimura, J. and T. Yoshida, Magma transport system beneath Norikura volcanic chains, Gekkan Chikyu (Earth Monthly), 18, 97-103, 1996 (in Japanese).

Ledo, J., C. Ayala, J. Pous, P. Queralt, A. Marcuello, and J. A. Munoz, New geophysical constraints on the deep structure of the Pyrenees, Geophys. Res. Lett., 27, 1037-1040, 2000.

Mackie, R. L., T. R. Madden, and P. E. Wannamaker, Three-dimensional magnetotelluric modeling using difference equations-theory and comparisons to integral equation solutions, Geophysics, 58, 215-226, 1993.

Mitsuhata, Y., Y. Ogawa, M. Mishina, T. Kono, T. Yokokura, and T. Uchida, Electromagnetic heterogeneity of the seismogenic region of 1962 M6.5 Northern Miyagi Earthquake, northeastern Japan, Geophys. Res. Lett., 28, 4371-4374, 2001

Mizoue, M. and Y. Ishiketa, Detection of melting zone beneath fault area of the 1984 Western Nagano Prefecture Earthquake and beneath southeastern foot of Mt. Ontake, Gekkan Chikyu (Earth Monthly), 10, 700-705, 1988 (in Japanese).

New Energy and Industrial Technology Development Organization (NEDO), Investigation report of the geothermal development promotion (Otaki area), No. 17, 1988.

Ogawa, Y. and T. Uchida, Two dimensional magnetotelluric inversion assuming Gaussian static shift, Geophys. J. Int., 126, 69-76, 1996.

Ogawa, Y., M. Mishina, T. Goto, H. Satoh, N. Oshiman, T. Kasaya, Y. Takahashi, T. Nisitani, S. Sakanaka, M. Uyeshima, Y. Takahashi, Y. Honkura, and M. Matsushima, Magnetotelluric imaging of fluids in intraplate earthquakes zones, NE Japan back arc, Geophys. Res. Lett., 28, 3741-3744, 2001.

Ogawa, Y., S. Takakura, and Y. Honkura, Resistivity structure across Itoigawa-Shizuoka tectonic line and its implications for concentrated deformation, Earth Planets Space, 54, 1115-1120, 2002.

Saeki, T. and Y. Umeda, Shear-wave polarizations in the rupture region of the 1984 Western Nagano Prefecture Earthquake, Zisin, 41, 163-171, 1988.

Sano, Y., Y. Nakamura, and H. Wakita, ${ }^{3} \mathrm{He} /{ }^{4} \mathrm{He}$ ratio anomalies associated with the 1984 Western Nagano Earthquake: Possibly induced by a diapiric magma, J. Geophys. Res., 91, 12291-12295, 1986.

Sano, Y., Y. Nishio, S. Sasaki, T. Gamo, and K. Nagao, Helium and carbon isotope systematics at Ontake Volcano, Japan, J. Geophys. Res., 103, 23863-23873, 1998.

Shichi, R., A. Yamamoto, A. Kimura, and H. Aoki, Gravimetric evidences for active faults around Mt. Ontake, central Japan: Specifically for hidden faulting of the 1984 Western Nagano Prefecture Earthquake, J. Phys. Earth, 40, 459-478, 1992.

Shuto, T. and T. Otsuka, Late Jurassic-earliest Cretaceous accretionary complex of the eastern Mino Terrane, central Japan: Radiolarian age and imbricate structure of the Misogawa Complex, J. Geol. Soc. Japan, 110, 67-84, 2004.

Takeda, J., Y. Iio, Y. Kobayashi, K. Yamamoto, H. Sato, S. Ohmi, H. Ito, R. Ikeda, and E. Yamamoto, The relationship between seismicity and fluid existing in the crust inferred from Vp/Vs Ratio, Zisin, 51, 419-430, 1999 (in Japanese with English abstract).

Tanabe, S., Time variation in seismic reflector around Mt. Ontake, M. Sc. Thesis, Earth and Planetary Science, Kyoto Univ., 40 pp., 1996.

Tank, S. B., Y. Honkura, Y. Ogawa, N. Oshiman, M. K. Tuncer, C. Celik, E. Tolak, and A. M. Isikara, Resistivity structure in the western part of the fault rupture zone associated with the 1999 Izmit earthquake and its seismogenic implication, Earth Planets Space, 55, 437-442, 2003.

Umeda, Y. and K. Ito, A model for the prediction of intraplate large earthquake growing in the inhomogeneous crust, Zisin, 50, 263-272, 1998 (in Japanese with English abstract).

Yamada, N. and T. Kobayashi, Geology of the Ontakesan district, Geological Sheet Map at 1:50,000, Geological Survey. Japan, 136 p., 1988 (in Japanese with English abstract).

T. Kasaya (e-mail: tkasa@jamstec.go.jp) and N. Oshiman 